\title{
Produção de couve chinesa em função da fertirrigação nitrogenada e potássica nas mudas
}

\author{
Antonio Ismael Inácio Cardoso'; Maria Beatriz S Piedade²; Júlia Maria Rodrigues ${ }^{1}$; Luiz Eduardo Ricardo ${ }^{1}$ \\ ${ }^{1}$ Universidade Estadual Paulista (UNESP), Botucatu-SP, Brasil; ismaeldh@fca.unesp.br; juliarodrigues.m@gmail.com; luiz_tnk@hotmail. \\ com; ${ }^{2}$ Escola Superior de Agricultura “Luiz de Queiroz” (ESALQ), Piracicaba-SP, Brasil; mbspiedade@gmail.com
}

\section{RESUMO}

Frente à existência de poucos estudos relacionados à aplicação de nitrogênio e potássio na produção de mudas de Brassicáceas, objetivou-se avaliar os efeitos de doses de nitrogênio e potássio, fornecidos por fertirrigação às mudas produzidas em substrato à base de fibra de coco, na produção de couve chinesa. Foram estudados 16 tratamentos, resultantes do fatorial quatro doses de $\mathrm{N}(0,80,160$ e $240 \mathrm{mg} / \mathrm{L})$ x quatro doses de $\mathrm{K}_{2} \mathrm{O}(0,100,200$ e $300 \mathrm{mg} / \mathrm{L})$, no delineamento experimental em blocos ao acaso, com quatro repetições. A semeadura do híbrido Kukai 65 foi realizada em bandejas de polipropileno com 200 células, preenchida com substrato de fibra de coco, em 13/01/2014. A adubação foi realizada por fertirrigação aos 7, 14 e 21 dias após a semeadura (DAS) utilizando-se $500 \mathrm{~mL}$ da solução em cada aplicação em cada parcela, constituída por 50 células. Após o transplantio, todas as plantas receberam o mesmo manejo, incluindo a adubação de plantio e em cobertura. Houve aumento linear crescente para todas as características vegetativas da parte aérea das mudas e ajuste quadrático para a massa seca das raízes (30 DAS), em função da adubação nitrogenada. O aumento das doses de potássio proporcionou redução linear da característica massa da matéria seca das raízes e linear crescente para altura e massa da matéria fresca da parte aérea das mudas. Foram observados ajustes quadráticos para número de folhas, altura e massa da matéria seca das plantas avaliadas na colheita (96 DAS) em função das doses de $\mathrm{N}$, estimando-se valores máximos de 47,7 folhas, $35,5 \mathrm{~cm}$ e $68 \mathrm{~g}$, para as doses de 101, 131 e $138 \mathrm{mg} / \mathrm{L}$ de N, respectivamente. Para as doses de potássio foi observado ajuste linear decrescente para a altura de planta e quadrático para massa fresca por planta, sendo 140 $\mathrm{mg} / \mathrm{L}$ de $\mathrm{K}_{2} \mathrm{O}$ a dose estimada para se obter a maior massa fresca por planta $(1,56 \mathrm{~kg})$ na colheita.

Palavras-chave: Brassica pekinensis, adubação, nitrogênio, potássio, propagação sexuada, fibra de coco.

\begin{abstract}
Chinese cabbage production in function of nitrogen and potassium fertigation of seedlings

Few researches are available about the influence of nitrogen and potassium application in brassica seedlings production; so, we aimed to evaluate the effect of rates of nitrogen and potassium, provided by fertigation to seedlings produced in coconut fiber substrate, on chinese cabbage production. Sixteen treatments were studied, resulted from the factorial four $\mathrm{N}$ rates $(0,80,160$ and $240 \mathrm{mg} / \mathrm{L}) \mathrm{x}$ four $\mathrm{K}_{2} \mathrm{O}$ rates $(0,100,200$ and $300 \mathrm{mg} / \mathrm{L})$, in the completely randomized block design, with four repetitions. Sowing of hybrid Kukai 65 was done in polypropylene trays with 200 cells, filled with coconut fiber, in January 13, 2014. Fertilization was done by fertigation at 7, 14 and 21 days after sowing (DAS), using $500 \mathrm{~mL}$ of solution in each application in each plot, consisting of 50 cells. After transplantation, all plants received the same cultural practices, including initial and top-dressing fertilization. There was a linear increasing for all aboveground part vegetative traits of seedlings (30 DAS) the higher de $\mathrm{N}$ rate was observed, and quadratic effect for roots dry matter. The increase of potassium rates resulted in decreasing linear effect for root dry weight of seedlings and increasing linear effect for height and fresh weight of aboveground part of seedlings. Quadratic effects were observed for number of leaves, height and dry weight of plants for $\mathrm{N}$ rates evaluated at harvesting (96 DAS), with maximum estimated in 47.7 leaves, $35.5 \mathrm{~cm}$ and $68 \mathrm{~g}$, for rates of 101,131 and $138 \mathrm{mg} / \mathrm{L}$ of $\mathrm{N}$, respectively. For K rates, decreasing linear effect for plant height was observed and quadratic for number of leaves and fresh weight of plants, and the highest fresh weight of plants $(1.56 \mathrm{~kg})$ at harvesting was estimated for rate of $140 \mathrm{mg} / \mathrm{L}$ of $\mathrm{K}_{2} \mathrm{O}$.
\end{abstract}

Keywords: Brassica pekinensis, fertilization, nitrogen, potassium, sexual propagation, coconut fiber.

(Recebido para publicação em 31 de março de 2016; aceito em 7 de agosto de 2017) (Received on March 31, 2016; acceptet on August 7, 2017)

\begin{abstract}
$\mathrm{A}$ s inúmeras espécies de hortaliças da família Brassicaceae apresentam grande importância na alimentação humana, seja pela quantidade consumida, pelo alto valor nutricional ou por sua elevada produtividade. Dentre estas espécies, tem-se a couve chinesa (Brassica pekinensis). É propagada por
\end{abstract}

sementes, com produção de mudas em bandejas específicas para este fim (Filgueira, 2008).

A produção de mudas consiste em uma das etapas mais importantes do sistema produtivo hortícola, necessitando utilização de insumos de alta qualidade, sendo o substrato um dos insumos de maior importância. O manejo correto e o tipo de substrato agrícola exercem influência significativa na formação do sistema radicular das plantas e, portanto, podem interferir no estado nutricional e na produção (Minami, 2010).

A fibra da casca do coco verde é uma matéria prima importante na produção 
de substratos para o cultivo de mudas. A facilidade de produção, baixo custo e alta disponibilidade são algumas vantagens apresentadas por este tipo de substrato, além de ser um produto renovável. No entanto, o substrato feito a partir das fibras de coco é pobre em nutrientes essenciais para as plantas e há necessidade de fornecê-los de acordo com as exigências da espécie a ser cultivada, podendo ser adicionado adubo em pré-plantio ou, principalmente, em fertirrigação (Carrijo et al., 2002).

Nota-se que há grande carência de informações no que diz respeito ao manejo das mudas, envolvendo substratos, irrigação, fertirrigação, dentre outros. Trabalhos que tratam de adubação de mudas conduzidas em substratos pobres em nutrientes são escassos. Existem estudos em abóbora (Higuti et al., 2010), berinjela (Oliveira et al., 2009), chicória (Cardoso \& Ustulim Filho, 2013), melancia (Ramos et al., 2012), pimenta (Pagliarini et al., 2012) e tomate (Costa et al., 2007; Sampaio et al., 2008). Além da escassez de pesquisas, a maioria dos trabalhos é interrompida na fase de transplantio, sem avaliar o efeito sobre a produção. Tendo em vista o exposto, objetivou-se avaliar os efeitos de doses de nitrogênio e potássio, fornecidos por fertirrigação às mudas produzidas em substrato a base de fibra de coco, na produção de couve chinesa.

\section{MATERIAL E MÉTODOS}

O trabalho foi desenvolvido na Fazenda Experimental São Manuel, localizada no município de São Manuel-SP, pertencente à Faculdade de Ciências Agronômicas da Universidade Estadual Paulista, Campus de Botucatu-SP (22 46 'S; 48 34'O; altitude de $740 \mathrm{~m}$ ). O clima da região, conforme os critérios adotados por Köppen, baseado nas observações meteorológicas, é Cfa, clima temperado quente (mesotérmico) úmido (Cunha \& Martins, 2009). No período do experimento, 13/01/2014 a 09/04/2014, as médias das temperaturas máxima, média e mínima foram de 29,6; 23,3 e $17,1^{\circ} \mathrm{C}$, respectivamente.

As mudas foram produzidas em es- tufa agrícola não climatizada, tipo arco, com pé direito de $2,8 \mathrm{~m}$, largura de $7 \mathrm{~m}$, comprimento de $20 \mathrm{~m}$ e cobertura de polietileno transparente de $150 \mu \mathrm{m}$ de espessura, com tela anti-afídeos nas laterais para impedir a entrada de insetos.

As mudas foram transplantadas para um Latossolo Vermelho distrófico típico. Os resultados obtidos na análise química, na camada de $0-20 \mathrm{~cm}$ de profundidade, antes da instalação do experimento foram: $\mathrm{pH}_{(\mathrm{CaCl} 2)}=5,9$; matéria orgânica $=7 \mathrm{~g} / \mathrm{dm}^{3} ; \mathrm{P}_{\text {resina }}=69 \mathrm{mg} / \mathrm{dm}^{3}$; $\mathrm{H}+\mathrm{Al}=13 \mathrm{mmol}_{\mathrm{c}} / \mathrm{dm}^{3} ; \mathrm{K}=1,8 \mathrm{mmol}_{\mathrm{c}} /$ $\mathrm{dm}^{3} ; \mathrm{Ca}=16 \mathrm{mmol}_{\mathrm{c}} / \mathrm{dm}^{3} ; \mathrm{Mg}=6 \mathrm{mmol}_{\mathrm{c}} /$ $\mathrm{dm}^{3} ; \mathrm{CTC}=37 \mathrm{mmol} / \mathrm{dm}^{3}$ e V= $64 \%$.

Foram estudados 16 tratamentos resultantes do fatorial quatro doses de $\mathrm{N}(0,80,160$ e $240 \mathrm{mg} / \mathrm{L}) \times$ quatro doses de $\mathrm{K}_{2} \mathrm{O}(0,100,200$ e $300 \mathrm{mg} / \mathrm{L})$, utilizando-se nitrato de amônio ( $34 \%$ de $\mathrm{N})$ e cloreto de potássio $\left(60 \%\right.$ de $\left.\mathrm{K}_{2} \mathrm{O}\right)$ como fontes de $\mathrm{N}$ e $\mathrm{K}$, respectivamente. Para a definição dos tratamentos, considerou-se a solução de Hoagland \& Arnon (1983), citados por Resh (1996), onde os valores de $\mathrm{N}_{-} \mathrm{NO}_{3}$ e de $\mathrm{K}_{2} \mathrm{O}$ são de 210 e $230 \mathrm{mg} / \mathrm{L}$, respectivamente. Considerando-se que na fase de plântula as exigências nutricionais são menores que na fase de planta adulta, foram estudadas doses inferiores às desta solução, exceto a maior dose de cada nutriente estudado. Além disto, pela experiência em pesquisas anteriores, excesso de nitrogênio nesta fase de plântula pode deixar a muda muito "mole" e estiolada, ou seja, de qualidade inferior. A fertirrigação foi feita de acordo com os tratamentos aos 7, 14 e 21 dias após a realização da semeadura. Foram utilizados $500 \mathrm{~mL}$ da solução por parcela em cada data, aplicados com um regador de crivo fino. A aplicação foi feita em cada parcela individualmente para garantir a mesma quantidade de solução.

Nesta etapa, o delineamento experimental foi em blocos ao acaso, com quatro repetições e 50 plantas por parcela, sendo 24 úteis. As mudas foram produzidas em bandejas de polipropileno (plástico) com 200 células, sendo mantidas cinco linhas com dez células, para cada parcela, seguida de duas linhas vazias. Das cinco linhas, a primeira e a última foram usadas como bordadura, assim como as primeiras e as últimas colunas.

Foi utilizado o substrato comercial Golden Mix $(\mathrm{C} / \mathrm{N}=63 / 1 ; \mathrm{pH}=4,50$; $\mathrm{Um} .=21,30 \% ; \mathrm{N}=0,76 \%$ da matéria seca (MS); $\mathrm{P}_{2} \mathrm{O}_{5}=0,34 \% \mathrm{MS} ; \mathrm{K}_{2} \mathrm{O}=$ $1,22 \% \mathrm{MS} ; \mathrm{Ca}=0,69 \% \mathrm{MS} ; \mathrm{Mg}=$ $0,25 \%$ MS; $\mathrm{S}=0,41 \% \mathrm{MS}$; M.O.= $86,00 \% \mathrm{MS} ; \mathrm{C}=47,80 \% \mathrm{MS} ; \mathrm{Na}=500$ $\mathrm{mg} / \mathrm{kg} \mathrm{MS} ; \mathrm{Cu}=100 \mathrm{mg} / \mathrm{kg} \mathrm{MS} ; \mathrm{Fe}=$ $2600 \mathrm{mg} / \mathrm{kg} \mathrm{MS} ; \mathrm{Mn}=266 \mathrm{mg} / \mathrm{kg}$ MS; $\mathrm{Zn}=14,8 \mathrm{mg} / \mathrm{kg} \mathrm{MS}$ ), composto por fibras do mesocarpo de cascas de coco. Procedeu-se ao destorroamento do substrato, deixando-o bem solto. Foram adicionados 30 litros de água para 107 litros de substrato, ficando a mistura em repouso por 2 horas, antes de encher as bandejas, conforme recomendação da empresa fornecedora.

Além do $\mathrm{N}$ e do $\mathrm{K}$, foram aplicados os demais macronutrientes de acordo com a solução de Hoagland \& Arnon (1983), citados por Resh (1996): P (31 $\mathrm{mg} / \mathrm{L}), \mathrm{Ca}(160 \mathrm{mg} / \mathrm{L}), \mathrm{Mg}(48 \mathrm{mg} / \mathrm{L})$ e S (64 mg/L), utilizando-se superfosfato triplo ( $41 \%$ de $\mathrm{P}_{2} \mathrm{O}_{5}$ e $10 \%$ de $\left.\mathrm{Ca}\right)$, cloreto de cálcio ( $24 \%$ de $\mathrm{Ca})$ e sulfato de magnésio ( $11 \%$ de $\mathrm{S}$ e $9 \%$ de $\mathrm{Mg}$ ).

A semeadura do híbrido Kukai 65 foi feita dia 13 de janeiro e o transplantio, em canteiros a campo, no dia 12 de fevereiro de 2014. No campo, foram mantidas as parcelas originais das bandejas, com as mesmas quatro repetições em delineamento em blocos ao acaso, sendo dez plantas por parcela no espaçamento de $70 \mathrm{~cm}$ entre linhas e de $30 \mathrm{~cm}$ entre plantas. A irrigação foi feita com microaspersores, instalados a cada $6 \mathrm{~m}$. A irrigação foi feita todos os dias com cerca de $3 \mathrm{~mm}$ de lâmina de água, exceto quando a precipitação diária excedia este valor.

A adubação foi baseada na recomendação de Raij et al. (1997) para brócolis e couve-flor, que pertencem à mesma família e gênero da couve chinesa, para o estado de São Paulo, aplicando-se 60, 200 e $180 \mathrm{~kg} / \mathrm{ha}$ de $\mathrm{N}, \mathrm{P}_{2} \mathrm{O}_{5}$ e $\mathrm{K}_{2} \mathrm{O}$ na forma de sulfato de amônia $(21 \% \mathrm{~N})$, superfosfato triplo $\left(41 \% \mathrm{P}_{2} \mathrm{O}_{5}\right)$ e cloreto de potássio $\left(60 \% \mathrm{~K}_{2} \mathrm{O}\right)$, respectivamente, além de 60 t/ha de composto orgânico da marca comercial Provaso.

Foram realizadas adubações em cobertura a cada sete dias, iniciando-se aos 14 dias após o transplantio, com 1,6 
g de sulfato de amônio $(21 \% \mathrm{~N})$ e 0,3 $\mathrm{g}$ de cloreto de potássio $\left(60 \% \mathrm{~K}_{2} \mathrm{O}\right)$ por planta em cada aplicação, totalizando 48 e $26 \mathrm{~kg} / \mathrm{ha}$ de $\mathrm{Ne} \mathrm{K}_{2} \mathrm{O}$, respectivamente.

O controle fitossanitário foi realizado de acordo com as necessidades da cultura e o controle de plantas daninhas foi por meio de capinas.

As avaliações foram realizadas no transplantio e na colheita, sendo que no dia do transplantio das mudas foram amostradas dez plântulas de cada parcela para avaliar as seguintes características: número de folhas (as folhas foram contadas, sem considerar os cotilédones, obtendo-se a média por plântula), altura da parte aérea (medida da base do hipocótilo até o ápice da muda, com auxílio de um paquímetro digital), massa da matéria fresca e seca da parte aérea (as mudas foram cortadas rente ao substrato e pesadas em balança analítica com valores expressos em miligrama por plântula) e massa da matéria seca das raízes (após a retirada da parte aérea, as raízes foram separadas do substrato sendo lavadas em água corrente sobre uma peneira, depois foram secadas e pesadas em balança analítica, com valores expressos em miligrama por plântula). A matéria seca foi obtida após secagem em estufa de circulação forçada de ar por 72 horas, com temperatura variando de 65 a $70^{\circ} \mathrm{C}$.

Na colheita, que foi realizada no dia 09 de abril de 2014, foram avaliadas a produção, que consistiu na avaliação das "cabeças", onde retirou-se todas as folhas externas. Em uma amostra de cinco plantas centrais por parcela foram avaliadas as características de altura da parte aérea, diâmetro das plantas (medição do maior diâmetro da planta com auxilio de paquímetro), número de folhas por planta (destacadas e contadas as folhas ainda verdes, obtendo-se a média por planta) e massa da matéria fresca (produção) e seca da parte aérea (pesagem das plantas em balança analítica com valores expressos em grama por planta). A matéria seca foi obtida após secagem em estufa de circulação forçada de ar, com temperatura variando de 65 a $70^{\circ} \mathrm{C}$, até atingirem massa constante.

Os resultados foram submetidos à análise de variância (fatorial quatro doses de $\mathrm{N} x$ quatro doses de $\mathrm{K}_{2} \mathrm{O}$ ) e foi realizada a análise de regressão para verificar o efeito das doses nas características avaliadas. Os dados foram processados pelo programa estatístico SISVAR 5.3 (Ferreira, 2010).

\section{RESULTADOS E DISCUSSÃO}

A interação doses de nitrogênio por doses de potássio não foi significativa para todas as características analisadas, permitindo a discussão de cada nutriente isoladamente.

Para todas as características avaliadas da parte aérea na fase de mudas foram obtidos ajustes lineares em função das doses de nitrogênio. Para a altura das plântulas as médias variaram de $70,28 \mathrm{~mm}$ da dose $0 \mathrm{mg} / \mathrm{L}$ para 124,66 $\mathrm{mm}$ para a dose mais alta $(240 \mathrm{mg} / \mathrm{L})$ (Figura 1). Gordin et al. (2010) também observaram maior altura de parte aérea com aumento da dose de fertilizantes via fertirrigação em mudas de couve chinesa.

A média do número de folhas por planta passou de 3,66 na dose $0 \mathrm{mg} / \mathrm{L}$ para 4,66 com $240 \mathrm{mg} / \mathrm{L}$ (Figura 1). Os valores obtidos estão próximos do relatado por outros autores para outras brassicáceas. Godoy \& Cardoso (2005) em couve-flor, Magro et al. (2011) em repolho, obtiveram mudas com 3 a 5 folhas e Tessaro et al. (2013) em couve chinesa, obtiveram de 3 a 4 folhas, sendo que Filgueira (2008) sugere que as mudas sejam transplantadas com cerca de 4 folhas, ou seja, valor próximo do obtido nesta pesquisa.

A média da massa da matéria fresca por plântula foi de $820 \mathrm{mg}$ na dose 0 $\mathrm{mg} / \mathrm{L}$ e de $2340 \mathrm{mg}$ na dose máxima de $240 \mathrm{mg} / \mathrm{L}$ e para massa da matéria seca as médias para as doses mínima e máxima foram de 73,31 e 155,15 mg, respectivamente (Figura 1).

Todas as características vegetativas da parte aérea estudadas apresentaram ajustes lineares positivos em relação às doses de nitrogênio, concordando com o apresentado por Malavolta (2006) que afirma que o nitrogênio tem importância fundamental nos processos de absorção iônica, fotossíntese, respiração, multi- plicação e diferenciação celular, entre outros, o que explica o aumento no número de folhas e massa da matéria fresca e seca. Também Filgueira (2008) cita que o $\mathrm{N}$ favorece o desenvolvimento vegetativo da planta. Resultados semelhantes foram relatados por Higuti et al. (2010) e Cardoso \& Ustulim Filho (2013) com a produção de mudas de abobrinha e chicória, respectivamente, também com substrato à base de fibra de coco, com maiores valores de massa da matéria fresca e seca quanto maior a dose de $\mathrm{N}$ na fertirrigação das mudas.

Para massa da matéria seca das raízes foi obtido ajuste de ordem quadrática com máximo valor estimado de 16,93 $\mathrm{mg}$ na dose de $158 \mathrm{mg} / \mathrm{L}$ de $\mathrm{N}$ (Figura 1), mostrando que excesso de $\mathrm{N}$ pode ser prejudicial ao desenvolvimento das raízes.

Em relação ao potássio, para a altura e a massa da matéria fresca da parte aérea das mudas (Figura 2) foram obtidos ajustes lineares crescentes. Já para a massa da matéria seca das raízes foi obtida resposta linear decrescente para o potássio, com médias variando entre 16,75 e $13,47 \mathrm{mg}$, da dose mínima para a máxima, respectivamente.

Apesar de ter havido aumento nas características da parte aérea com as doses de potássio, estes aumentos foram menos expressivos que para o nitrogênio. Por exemplo, as médias da massa da matéria fresca da parte aérea variaram de 820 a $2340 \mathrm{mg}$ da menor para a maior dose de N (Figura 1), enquanto que para o potássio a variação foi bem menor, de 1517 a 1642 mg (Figura 2). Estes resultados comprovam o maior efeito do nitrogênio, em comparação ao potássio, nas características vegetativas das mudas, conforme relatado por Higuti et al. (2010) e Cardoso \& Ustulim Filho (2013), em abobrinha e chicória, respectivamente. Além disto, a fibra de coco ainda pode ser fonte de potássio para as plantas, conforme relatado por Dias et al. (2009) e Oliveira et al. (2009), ou seja, mesmo na testemunha (dose $0 \mathrm{mg} / \mathrm{L}$ de potássio) as raízes tinham algum potássio disponível para ser absorvido.

O sistema radicular mostrou-se sensível às maiores doses de nitrogênio (ajuste quadrático, Figura 1) e ao 
aumento das doses de potássio (ajuste linear decrescente, Figura 2), talvez por excesso de sais. Portanto, apesar da parte aérea ter sido beneficiada pelo aumento nas doses de nitrogênio e de potássio, as raízes mostram uma resposta diferenciada, provavelmente por estarem em contato direto com os sais aplicados. O cloreto de potássio é um dos fertilizantes com maior efeito salino, o que pode explicar o efeito decrescente para o K. Também Nascimento et al.
(2011), Oliveira et al. (2014) e Schmitt et al. (2016) observaram que excesso de sais na solução nutritiva prejudica a formação de raízes de pimentão, pimenta e morango, respectivamente.

Para as características relacionadas à produção no final do ciclo, para as doses de nitrogênio obteve-se ajuste quadrático para o número de folhas, altura e massa da matéria seca por planta (Figura 3). Apesar de significativo, a diferença entre o maior e o menor valor foi pequena. Para número de folhas o menor valor (46,6 folhas) foi obtido na maior dose, enquanto o maior valor foi de 47,7 folhas para a dose $102 \mathrm{mg} / \mathrm{L}$ de N (Figura 3). Para altura os valores variaram de $34,0 \mathrm{~cm}$ (testemunha, dose $0 \mathrm{mg} / \mathrm{L})$ a $35,5 \mathrm{~cm}(131 \mathrm{mg} / \mathrm{L}$ de $\mathrm{N})$ e para massa da matéria seca, de $65 \mathrm{~g}$ (testemunha, dose $0 \mathrm{mg} / \mathrm{L})$ a $69 \mathrm{~g}(138$ $\mathrm{mg} / \mathrm{L}$ de N). As outras características não diferiram em função das doses de nitrogênio, com médias de 1517 g para

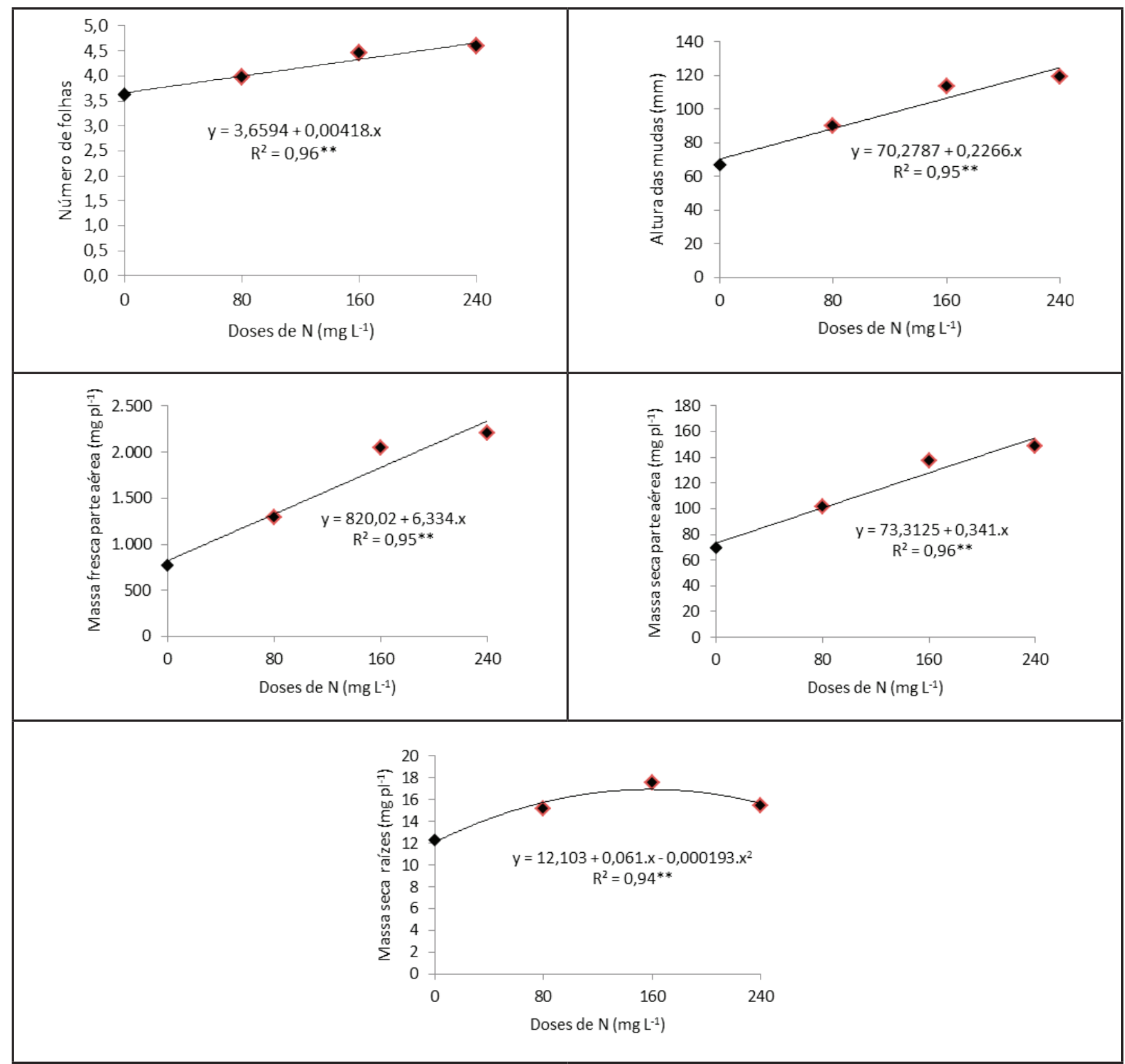

Figura 1. Número de folhas, altura, massa da matéria fresca e seca da parte aérea e seca das raízes das mudas de couve chinesa em função das doses de nitrogênio (number of leaves, height, fresh and dry matter of shoots and dry matter of roots of chinese cabbage seedlings in function of nitrogen rates). São Manuel, UNESP, 2014. 


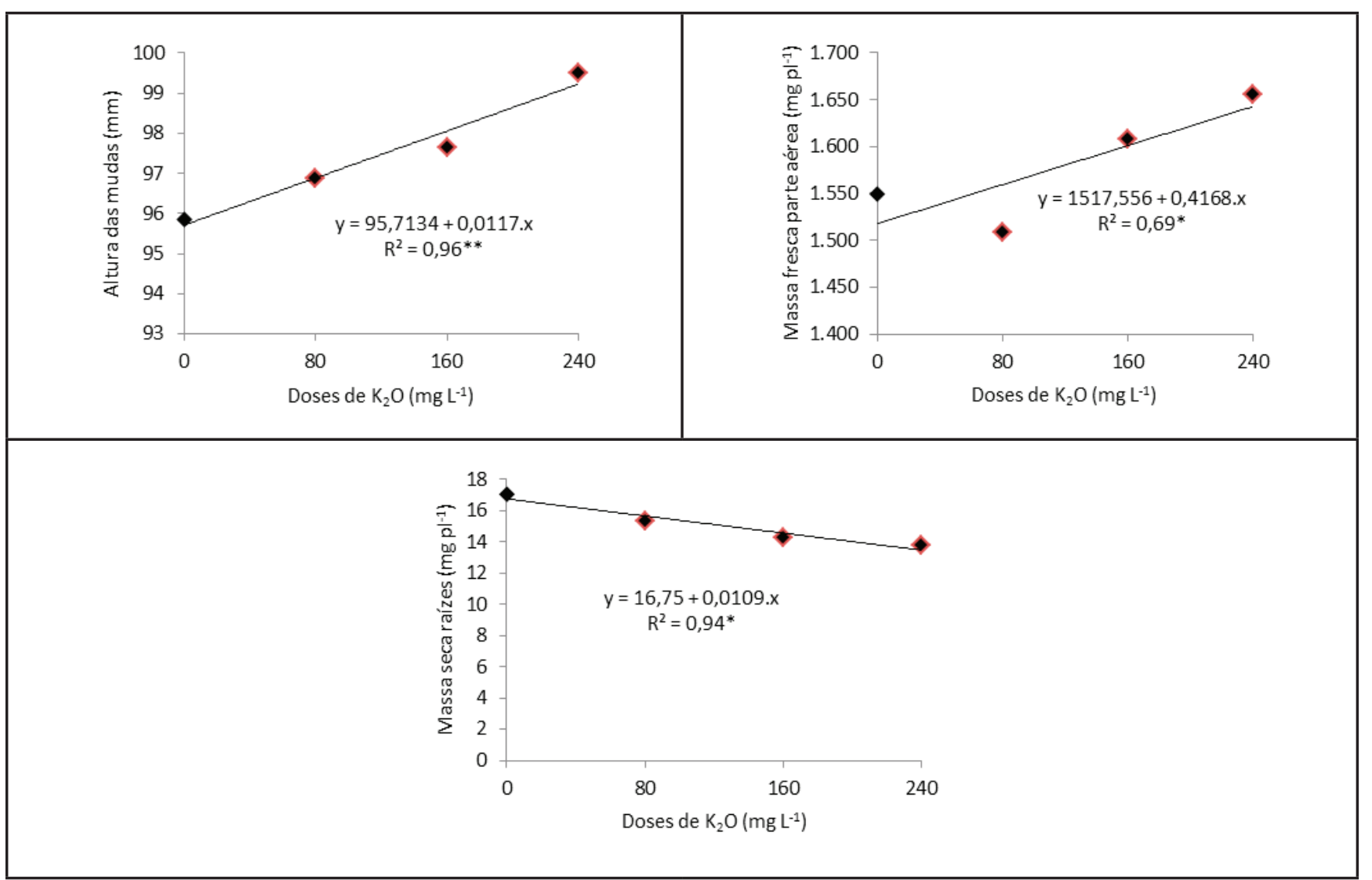

Figura 2. Altura, massa da matéria fresca da parte aérea e seca das raízes das mudas de couve chinesa em função das doses de potássio (height, fresh matter of shoot and dry matter of roots of chinese cabbage seedlings in function of potassium rates). São Manuel, UNESP, 2014.

massa de matéria fresca por planta e 22,8 $\mathrm{cm}$ para o diâmetro da planta.

Os resultados para as doses de $\mathrm{N}$ para as características em que houve efeito (número de folhas, altura e massa da matéria seca) apresentaram ajustes estatísticos semelhantes aos observados para as características de raízes na fase de mudas, ou seja, ajuste quadrático e as doses que resultaram em máximos valores na colheita $(102,131$ e $138 \mathrm{mg} / \mathrm{L}$, para número de folhas, altura e massa da matéria seca, Figura 3), não foram muito diferentes das doses em que se obteve o máximo de matéria seca das raízes ( 158 $\mathrm{mg} / \mathrm{L}$ de N, Figura 1). Portanto, aparentemente, o efeito da fertirrigação com $\mathrm{N}$ nas raízes é mais importante para o bom desenvolvimento após o transplantio até a colheita do que o efeito da fertirrigação sobre a parte aérea das mudas. Segundo Minami (2010), nem sempre as mudas maiores e/ou com maior massa serão as melhores, ou seja, que após o transplantio irão resultar na maior produtividade. Uma muda de qualidade é aquela que não sofre estresse com o transplantio e permite à planta desenvolver-se plenamente até o final do ciclo.

Quanto às doses de potássio, não se obteve efeito para diâmetro da planta (média de 22,8 cm). Para massa de matéria fresca e número de folhas por planta foram obtidos ajustes de ordem quadrática, com maior valor estimado em $1557 \mathrm{~g}$ na dose $140 \mathrm{mg} / \mathrm{L}$ de $\mathrm{K}_{2} \mathrm{O}$ e 47,6 folhas na dose $89 \mathrm{mg} / \mathrm{L}$ de $\mathrm{K}_{2} \mathrm{O}$, respectivamente (Figura 3). A massa da matéria fresca obtida é muito superior à relatada por Seabra Júnior et al. (2014), 584 a 924 g por planta. Além dos genótipos serem diferentes, a couve chinesa é uma espécie adaptada a clima ameno, o que ajuda a explicar os menores valores obtidos por estes autores na região de Cáceres-MT. Também Ito et al. (2006) relataram valores pouco inferiores de massa fresca comercial em estudo de cultivares em Jaboticabal-SP, com valores de 940 a $1380 \mathrm{~g} /$ planta. Para a altura das plantas houve ajuste linear decrescente, com os valores variando de $35,2 \mathrm{~cm}($ dose $0 \mathrm{mg} / \mathrm{L})$ a $34,5 \mathrm{~cm}$ na maior dose $\left(300 \mathrm{mg} / \mathrm{L}\right.$ de $\left.\mathrm{K}_{2} \mathrm{O}\right)$.
Novamente, para o potássio, apesar de algumas diferenças significativas estatisticamente, foram muito pequenas e quase imperceptíveis visualmente.

Após o transplantio, observou-se bom desenvolvimento das plantas de todos os tratamentos. Independentemente do tratamento (doses de $\mathrm{Ne} \mathrm{K}_{2} \mathrm{O}$ ), todas as plantas receberam os mesmos tratos, incluindo adubação de plantio e em cobertura, irrigação, manejo fitossanitário e controle de plantas daninhas. Assim, as grandes diferenças iniciais, principalmente para o $\mathrm{N}$, não se mantiveram com a mesma magnitude até o final do ciclo, com bom desenvolvimento das mudas no local definitivo.

Para as faixas de concentração avaliadas, o nitrogênio apresentou ajuste linear sobre as características vegetativas da parte aérea das mudas e quadrático para as das raízes, enquanto o potássio apresentou ajuste linear decrescente para massa seca das raízes e crescente para altura e massa fresca da parte aérea das mudas. Sugere-se doses entre 130 e $140 \mathrm{mg} / \mathrm{L}$ de $\mathrm{N}$ por propiciar maior 


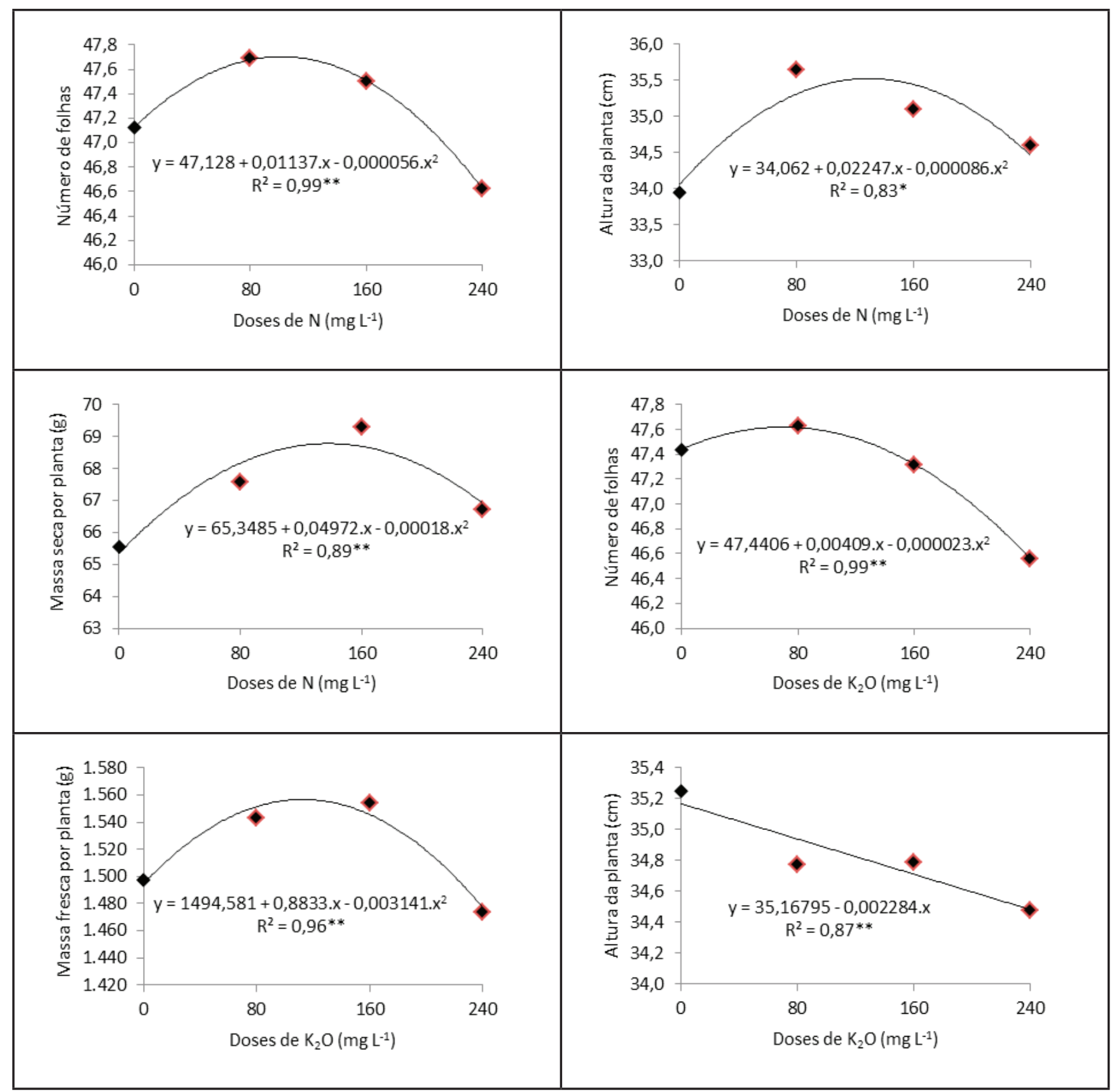

Figura 3. Número de folhas, altura e massa da matéria seca por planta na colheita em função das doses de nitrogênio; número de folhas, massa da matéria fresca e altura por planta na colheita em função das doses de potássio na fertirrigação das mudas (number of leaves, height and dry matter of plant at harvesting in function of nitrogen rates; number of leaves, fresh matter and height of plant at harvesting in function of potassium rates in the fertigation of seedlings). São Manuel, UNESP, 2014.

altura e massa da matéria seca por planta na colheita e cerca de $140 \mathrm{mg} / \mathrm{L}$ de $\mathrm{K}_{2} \mathrm{O}$ por proporcionar maior massa fresca por planta na colheita.

\section{REFERÊNCIAS}

CARDOSO, AII; USTULIM FILHO, AJ. 2013.
Produção de chicória em função de doses de nitrogênio e potássio aplicadas na fase de mudas. Horticultura Brasileira 31: 654-658.

CARRIJO, OA; LIZ, RS; MAKISHIMA, N. 2002. Fibra da casca do coco verde como substrato agrícola. Horticultura Brasileira 20: 533-536.

COSTA, CA; RAMOS, SJ; SAMPAIO, RA; GUILHERME, DO; FERNANDES, LA. 2007. Fibra de coco e resíduo de algodão para substrato de mudas de tomateiro. Horticultura Brasileira 25: 387-391.

CUNHA, AR; MARTINS, D. 2009. Classificação climática para os municípios de Botucatu e São Manuel, SP. Irriga 14: 1-11.

DIAS, TJ; PEREIRA, WE; CAVACANTE, LF; RAPOSO, RWC; FREIRE, JLO. 2009. Desenvolvimento e qualidade nutricional de mudas de mangabeiras cultivadas em substratos contendo fibra de coco e adubação fosfatada. Revista Brasileira de Fruticultura 31: 512-523.

FERREIRA, DF. 2010. Sisvar - Sistema de análise de variância. Versão 5.3. Lavras-MG: UFLA.

FILGUEIRA, FAR. 2008. Novo manual de 
olericultura: agrotecnologia moderna na produção e comercialização de hortaliças. Viçosa: UFV. 421p.

GODOY, MC; CARDOSO, AII. 2005. Produtividade da couve-flor em função da idade de transplantio das mudas produzidas e tamanhos de células na bandeja. Horticultura Brasileira 23: 837-840.

GORDIN, CRB; BISCARO, GA; SANTOS, AM; PAGLIARINI, MK; PEIXOTO, PPP. 2010. Níveis de fertirrigação nas características morfofisiológicas de mudas de couve chinesa. Revista Agrarian 3: 253-260.

HIGUTI, ARO; SALATA, AC; GODOY, AR; CARDOSO, AII. 2010. Produção de mudas de abóbora com diferentes doses de nitrogênio e potássio. Bragantia 69: 377-380.

ITO, LA; CHARLO, HCO; VARGAS, PF; CASTOLDI, RC; BRAZ, LT. 2006. Produtividade e qualidade de cinco híbridos de couve-chinesa em campo aberto. In: CONGRESSO BRASILEIRO DE OLERICULTURA, 46. Resumos... Goiânia: $\mathrm{ABH}$.

MAGRO, FO; SALATA, AC; BERTOLINI, EV; CARDOSO, AII. 2011. Produção de repolho em função da idade das mudas.Agro@mbiente On-line 5: 119-123.

MALAVOLTA, E. 2006. Manual de nutrição mineral de plantas. São Paulo: Ed. Agronômica Ceres. 638p.

MINAMI, K. 2010. Produção de mudas de alta qualidade em horticultura. Piracicaba: Degaspari. 440p.

NASCIMENTO, JAM; CAVALCANTE, LF; SANTOS, PD; SILVA, AS; VIEIRA, MS; OLIVEIRA, AP. 2011. Efeito da utilização de biofertilizante bovino na produção de mudas de pimentão irrigadas com água salina. Revista Brasileira de Ciências Agrárias 6: 258-264.

OLIVEIRA, AB; HERNANDEZ, FFF; ASSIS JÚNIOR, RN. 2009. Absorção de nutrientes em mudas de berinjela cultivadas em pó de coco verde. Caatinga 22: 139-143.

OLIVEIRA, FA; MEDEIROS, JF; LINHARES, PSF; ALVES, RC; MEDEIROS, AMA; OLIVEIRA, MKT. 2014. Produção de mudas de pimenta fertirrigadas com diferentes soluções nutritivas. Horticultura Brasileira 32: 458-463.

PAGLIARINI, MK; BISCARO, GA; GORDIN, CRB; SANTOS, AM; BRANDÃO NETO, JF. 2012. Avaliação das características morfofisiológicas em mudas de pimenta malagueta. Irriga 17: 46-55.

RAIJ, B; CANTARELLA, H; QUAGGIO, JA; FURLANI, AMC. 1997. Recomendações de adubação e calagem para o estado de São
Paulo. 2. ed. Campinas: Instituto Agronômico \& Fundação IAC. 285p.

RAMOS, ARP; DIAS, RCS; ARAGÃO, CA; MENDES, MAS. 2012. Mudas de melancia produzidas com substrato à base de pó de coco e soluções nutritivas. Horticultura Brasileira 30: 339-344.

RESH, HM. 1996. Hydroponic food production. $5^{\text {th }}$ ed. California: Woodbridge Press. 527p.

SAMPAIO, RA; RAMOS, SJ; GUILHERME, DO; COSTA, CA; FERNANDES, LA. 2008. Produção de mudas de tomateiro em substratos contendo fibra de coco e pó de rocha. Horticultura Brasileira 26: 499-503.

SEABRA JÚNIOR, S; PEREIRA, AS; ARAUJO, KL. 2014. Desempenho de cultivares de couve-chinesa em Cáceres-MT. Horticultura Brasileira 32: 504-507.

SCHMITT, OJ; ANDRIOLO, JL; SCHULTZ, E; LERNER, MA; SOUZA, JM; PICIO, MD. 2016. Produção de estolhos de cultivares de morangueiro em função da condutividade elétrica da solução nutritiva. Horticultura Brasileira 34: 294-301.

TESSARO, D; MATTER, JM; KUCZMAN, O; FURTADO, LF; COSTA, LAM; COSTA, MSSM. 2013. Produção agroecológica e desenvolvimento a campo de couve-chinesa. Ciência Rural 43: 831-837. 